\title{
Adultos com Deficiência Intelectual e Meios Digitais: Desenvolvimento Participativo de uma Campanha Audiovisual
}

\section{Adults with Intellectual Disabilities and Digital Media: Participatory Development of an Audiovisual Campaign}

\author{
Catarina Alves Marques*, Rita Santos**, Ana Margarida Almeida*** \\ * Departamento de Comunicação e Arte/Universidade de Aveiro \\ ** DigiMedia/Escola Superior de Tecnologia e Gestão de Águeda/Universidade de Aveiro \\ *** DigiMedia/Departamento de Comunicação e Arte/Universidade de Aveiro
}

Resumo

O presente artigo apresenta os resultados de um estudo que teve como objetivo o desenvolvimento participativo e avaliação de uma campanha audiovisual de sensibilização para a importância do uso dos meios digitais por parte de adultos com deficiência intelectual. O desenvolvimento da campanha envolveu um grupo de oito pessoas com deficiência intelectual, que colaborou nas fases de conceção, produção e pós-produção.

Numa primeira fase, através das entrevistas e pela observação durante as sessões de trabalho, foi possível caracterizar o perfil de experiência digital e audiovisual dos participantes. Posteriormente, procedeu-se ao desenvolvimento da campanha, tendo-se verificado que os contributos dos participantes com deficiência intelectual centraram-se na tomada de decisão, através de votações e, nas gravações, enquanto técnicos de imagem, som e elenco. Após o lançamento da campanha, aplicou-se um inquérito por questionário final que revelou a grande importância atribuída à temática e mostrou um feedback positivo relativamente à campanha audiovisual produzida, tanto em termos de conceção como ao nível de poder sensibilizador.

Palavras-chave: Meios Digitais; deficiência intelectual; design participativo; audiovisual; inclusão digital

Abstract

This article presents the results of a study that aimed the participatory development and evaluation of an audiovisual campaign to raise awareness of the importance of using digital media by adults with intellectual disability. The development of the campaign involved a group of 8 people with intellectual disabilities, who collaborated in the design, production and post-production.

In the first phase, through interviews and observation during the work sessions, it was possible to characterize the participants' digital and audiovisual experience profile. Subsequently, the participants with intellectual disability contributed to the campaign making decisions through voting and being cast technicians, recording image and sound. After the release of the campaign, a final questionnaire was applied, which showed a great importance assigned to the topic and a positive feedback regarding the audiovisual campaign produced, both in terms of conception and sensibilisation power.

Keywords: Digital media; intellectual disability; participatory design; audiovisual; digital inclusion

\section{Introdução}

As tecnologias digitais têm potencial na diminuição de muitas das barreiras a que as pessoas com deficiência estão sujeitas, uma vez que "by using computing technology for tasks such as reading and writing documents, communicating with others, and searching for information on the Internet, students and 
employees with disabilities are capable of handling a wider range of activities independently" (Burgstahler, 2012, p. 1). Os media digitais podem, assim, melhorar aa qualidade de vida das pessoas com deficiência, 0 que aprofunda a necessidade de promover o seu uso e ampliar a visibilidade dos seus efeitos positivos junto deste grupo populacional vulnerável. As iniciativas neste sentido são escassas, pelo que se revelou oportuno estudar os processos de desenvolvimento de uma campanha que alerte para os benefícios da utilização dos meios digitais para as pessoas com deficiência intelectual e, em simultâneo, demonstre que estas pessoas são capazes de realizar tarefas relacionadas com o desenvolvimento da própria campanha.

A investigação pretendeu atingir vários objetivos, nomeadamente: identificar as melhores estratégias para a conceção e realização da campanha de sensibilização de forma participativa; conhecer os usos das tecnologias pelos adultos com deficiência e como estes podem beneficiar a sua qualidade de vida; desenvolver uma campanha em design participativo com os adultos com deficiência intelectual que visa sensibilizar para a importância do uso dos meios digitais por parte deste grupo; observar o potencial de sensibilização da campanha na promoção e difusão do uso dos meios digitais pelos adultos com deficiência. O quadro teórico escolhido reflete uma preocupação com a definição de "deficiência intelectual" e a identificação dos seus diferentes níveis de profundidade, aprofundando a deficiência intelectual nos adultos, o grupo específico deste estudo. A importância da inclusão social é outro dos temas abordados, estando diretamente ligado com outro grande tema da investigação - os meios digitais e a inclusão digital. Pretendeu-se, portanto, conhecer melhor o contexto do uso dos meios digitais pelos adultos com deficiência, e refletir sobre o impacto que a utilização desses meios traz para a vida de adultos com deficiência.

Do ponto de vista do enquadramento, é ainda feita uma abordagem ao desenvolvimento de campanhas de sensibilização com recurso a meios audiovisuais que recorrem a estratégias de design participativo focando, em específico, a pertinência do envolvimento de adultos com deficiência neste processo.

Em termos de metodologia, o estudo realizado beneficiou sobretudo da investigação de desenvolvimento, embora se tenham aplicado ainda técnicas ligadas ao design participativo, à investigação-ação e à etnografia. O estudo foi desenvolvido em articulação com uma Associação que dá apoio a pessoas com deficiência intelectual, tendo sido realizada uma recolha de dados no sentido de determinar o perfil de experiência digital e audiovisual dos utentes dessa Associação, identificar os recursos de tecnologias da informação e comunicação da Associação e conhecer o tipo de atividades realizadas com estes recursos. Como o projeto recorreu a técnicas do design participativo, as sessões de trabalho com o envolvimento direto dos participantes e as discussões em grupo tiveram um papel determinante no processo. Por fim, considerou-se pertinente avaliar o potencial de sensibilização da campanha através da aplicação de um inquérito por questionário.

\section{Definição do conceito de Deficiência Intelectual}

A deficiência intelectual insere-se nos transtornos de desenvolvimento neurológico e é caracterizada por défices nas capacidades mentais, em geral, nos domínios conceptual, social e prático, nomeadamente na aprendizagem, raciocínio, comunicação interpessoal e autogestão (American Psychiatric Association, 2013). Até 2013, nas edições do Diagnostic and Statistical Manual of Mental Disorders da American Psychriatric Association, esta era denominada de atraso mental mas, por se estar a tornar incomum entre médicos e 
outros profissionais das áreas da educação e do direito, e por se considerar que esta terminologia se tornou ultrapassada, ofensiva e, consequentemente, inadequada (Harkin, 2010), a partir desse ano, na quinta edição (DSM-5), passa-se a admitir o termo deficiência intelectual em substituição dessa expressão. De modo a serem esclarecidas as relações com outros sistemas de classificação, como a $11^{\text {a }}$ revisão de International Classification of Diseases (ICD-11), o termo é acompanhado por "transtorno intelectual de desenvolvimento" (American Psychiatric Association, 2013).

Segundo a American Psychiatric Association, a deficiência intelectual tem quatro níveis de gravidade - suave, moderado, severo e profundo - que são determinados através do funcionamento adaptativo e não com base no Quociente de Inteligência (QI), uma vez que é o funcionamento adaptativo que define o nível de suporte necessário (American Psychiatric Association, 2013). Já a classificação da American Association on Intellectual and Developmental Disabilities é multidimensional e tem em consideração a construção da deficiência através de uma escala de intensidade com base na gravidade. Em vez de fazer a classificação pela gravidade das limitações funcionais, as necessidades são tipicamente identificadas usando esse instrumento padronizado, que categoriza o nível de funcionamento de cada pessoa com base no nível de apoio que a pessoa precisa para exercer um conjunto de funções razoavelmente bem no seu ambiente preferido (Reynolds, Zupanick \& Dombeck, 2013).

As principais características da deficiência intelectual são apresentadas no DSM-5 (American Psychiatric Association, 2013) segundo três critérios. O critério A refere-se, no geral, a défices nas capacidades mentais, interferindo no cumprimento de funções intelectuais como raciocínio, resolução de problemas, julgamento e na aprendizagem através da experiência. Englobado na área social e prática, o critério B está relacionado com as limitações do funcionamento adaptativo, que interfere nos padrões socioculturais e de desenvolvimento para independência e responsabilidade social. Isto resulta em dificuldades na capacidade de comunicação interpessoal e na habilidade de fazer e manter amizades, na esfera educativa, profissional e comunitária, por exemplo. O critério $\mathrm{C}$ está relacionado com o facto de as limitações intelectuais e adaptativas terem início durante o período de desenvolvimento (American Psychiatric Association, 2013).

\section{A importância da inclusão social}

As pessoas com deficiência, nomeadamente intelectual, fazem parte de grupos vulneráveis no sentido em que tendem a ser excluídas da sociedade, tanto a nível educacional, como económico, social e digital.

O facto de o termo inclusão social ser pouco claro causa dificuldades na comunicação entre os indivíduos com deficiência, as suas famílias, cuidadores e decisores políticos e, consequentemente, uma certa dormência na ação de mudança. Torna-se, pois, essencial que se clarifique este termo, uma vez que "social inclusion is for all of us: an individual with an intellectual or developmental disability; for people with intellectual and developmental disabilities as a group; for members of society who will benefit from their inclusion; and for nation states who can benefit from the participation of people with all levels of abilities" (Simplican, Leader, Kosciulek \& Leahy, 2015, p.22).

Existem dois tipos de enfoque nas definições de inclusão social: a conceção estrita, cuja importância recai sobre a comunidade; e a conceção ampla, que é intermutável com a inclusão, participação da comunidade e com o capital social, que pode também envolver relações significativas e recíprocas, emprego e apoios 
formais e informais (Simplican et al, 2015). Nesse sentido, Simplican, Leader, Kosciulek e Leahy (2015) apresentam um modelo focado nos domínios das relações interpessoais e da participação comunitária, referindo que estes domínios devem apoiar-se mutuamente e são essenciais para a qualidade de vida das pessoas com deficiência e necessários à inclusão social. Separando a definição de inclusão social dos processos que podem produzir inclusão social, bem como os sentimentos subjetivos que podem resultar da inclusão, os autores focam-se na especificação dos componentes das relações interpessoais e da participação da comunidade. Argumentando que as relações são essenciais e fornecem apoio social em termos emocionais, instrumentais e informacionais e que a participação da comunidade, através do envolvimento em atividades comunitárias, promove o desenvolvimento de relações interpessoais. Juntos, estes domínios formam os principais componentes da inclusão social. Embora definições contrastantes possam dificultar a implementação de medidas para promoção da inclusão social, também levantam questões sobre o propósito da inclusão social (Simplican etl, 2015).

A inclusão de pessoas com deficiência depende sobretudo das suas redes familiares sociais. Contudo, e pese embora os esforços dos últimos anos, mantém-se a tendência para colocar as pessoas com deficiência intelectual em estabelecimentos de educação especial ou em turmas separadas e em ambientes residenciais específicos para pessoas com deficiência. Este isolamento acaba por reduzir as experiências de interação social de muitos indivíduos com deficiência intelectual, limitando a sua capacidade de desenvolver redes sociais e participar em atividades correntes, particularmente fora da escola ou do ambiente de trabalho. Os portadores de deficiência são precisamente as pessoas que têm mais dificuldade em estabelecer relações de amizade sem ser com familiares, profissionais de saúde ou outras pessoas com deficiência, culminando este cenário num aprofundamento do seu isolamento e solidão (Gilmore \& Cuskelly, 2014).

Sabendo que para indivíduos com deficiência intelectual, cujas oportunidades de vida já estão limitadas em graus variados por fatores cognitivos e de saúde, os distúrbios de saúde mental, como depressão e ansiedade, podem ser desencadeados ou agravados pela solidão (Gilmore \& Cuskelly, 2014), Wilson, Jaques, Johnson e Brotherton (2016) ressalvam a urgência em encontrar novas intervenções para aumentar a atividade, inclusão social, contactos sociais e amizades de pessoas com deficiência intelectual. Os autores apoiam-se na premissa de que um aumento na participação comunitária conduz a um reforço das redes sociais e que as relações interpessoais que se tornam, consequentemente, mais robustas levam a um maior envolvimento na comunidade (Wilson et al., 2016).

Wilson et al. (2016) exploraram as experiências de um grupo de 10 adultos com deficiência intelectual, integrados num grupo de apoio social. Através da análise das entrevistas concluíram que a socialização melhora a saúde e o bem-estar, que o envolvimento social expande o círculo de amigos e que a conexão psicossocial desenvolve um sentimento de inclusão, embora seja importante ter um sistema de apoio que auxilie nesta questão. Os participantes explicitaram que a sua participação no grupo de apoio teve um impacto positivo nas suas vidas, principalmente a nível de relações de amizade (Wilson et al., 2016).

Os resultados benéficos da inclusão social incluem a melhoria da qualidade de vida, o aumento das competências sociais e da autoconfiança e ainda a melhoria da saúde menta (Wilson et al., 2016). Os investigadores argumentam que a inclusão social promove a felicidade, a autoestima, a confiança, a saúde mental, bem-estar e a capacidade de tomada de decisão. Essencialmente, a inclusão social melhora as vidas das pessoas com e sem deficiência (Simplican et al, 2015). 


\section{Cenários de acesso e uso dos meios digitais por pessoas com Deficiência Intelectual e transição para a vida ativa e participação social}

As tecnologias digitais podem melhorar a autonomia e o desenvolvimento das pessoas com deficiência, nomeadamente intelectual. Em muitos casos, as redes sociais e os grupos online (fóruns, grupos de discussão, chats, ...) constituem um meio de apoio alternativo às relações familiares. Assumindo-se, por vezes, como a única via para sustentar as relações sociais das pessoas com deficiência intelectual, são considerados meios sociais apropriados para incentivar a troca de apoio (Suria, 2017). Apesar disso, estudos sugerem que há uma "divisão tecnológica" no que diz respeito ao uso de meios digitais por pessoas com deficiência intelectual, quando comparado com as pessoas sem deficiência (Tanis et al., 2012), embora não se consiga saber com exatidão o número de pessoas com deficiência que acedem à internet, qual o uso que fazem e a qual a sua opinião acerca do que é benéfico para eles (Chadwick, Wesson \& Fullwood, 2013). As estatísticas levadas a cabo pelo Office for National Statistics do Reino Unido apuraram que, em 2016, 25\% dos adultos com deficiência nesse país nunca tinha acedido à internet e que a proporção de adultos que eram utilizadores recentes de internet era menor para as pessoas com deficiência em comparação com as pessoas sem deficiência (Office for National Statistics, 2016).

As pessoas com deficiência até podem ter acesso aos meios digitais mas muitas vezes não conseguem beneficiar completamente deles, como uma pessoa sem deficiência beneficiaria (Burgstahler, 2012), existindo duas principais razões para este fenómeno. A primeira deve-se às barreiras que são muitas vezes impostas a estes indivíduos aquando do uso do computador, nomeadamente no acesso, na interpretação dos dados de output e na parca documentação de suporte em formato acessível (Burgstahler, 2012). A segunda razão está relacionada com a falta de literacia digital que ainda se observa na grande maioria das pessoas com deficiência.

O caminho para a inclusão digital não está apenas relacionado com o acesso aos meios digitais, estando também ligado às competências necessárias para a sua utilização (Ala-Mutka, 2011). A literacia digital é muito mais do que a capacidade de utilizar dispositivos digitais; respeita ao domínio de várias capacidades (cognitivas, motoras, sociológicas e emocionais) que são necessárias para conseguir usar as ferramentas digitais de forma efetiva (Eshet-Alkalai, 2012). Segundo Eshet-Alkalai (2012) baseia-se na capacidade para compreender as mensagens através da sua exibição gráfica; para reprodução digital; para navegação não linear (hipertextual); para avaliar o teor da informação, nomeadamente a sua qualidade e validade; na capacidade socioemocional que permita seguir as "regras" do espaço virtual a aplicar na comunicação em rede; e, por último, na capacidade para o pensamento em tempo real para conseguir processar diversos estímulos em simultâneo (Eshet-Alkalai, 2012).

A literacia e inclusão digital têm sido alvo de atenção e preocupação de diversas Organizações, como a União Europeia. DigiComp 2.0 (Riina, Punie, Carretero \& van den Brande, 2016) apresenta a primeira fase de atualização do Quadro Europeu de Competências Digitais para os Cidadãos, publicado em 2013, que pretende servir de ferramenta para melhoria da competência digital dos cidadãos.

As pessoas com deficiência, sobretudo os adultos que não tiveram acesso a ensino qualificado e adaptado às suas necessidades, não possuem, na maior parte das vezes, as aptidões digitais necessárias para explorar ao máximo as potencialidades das TIC e, assim, beneficiar destas de forma significativa na vida, trabalho e aprendizagem. Com o aumento da utilização dos meios digitais, a investigação em torno do conceito de 
literacia digital deve, assim, considerar também as especificidades das pessoas com deficiência, na procura de aprofundar conhecimentos e deixar orientações para profissionais e investigadores neste âmbito. Alsalem (2016) refere que um dos passos iniciais será investigar a relação entre literacia digital e as particularidades dos alunos com deficiência tendo em consideração os vários dispositivos auxiliares de leitura, escrita e interação com o conteúdo.

Pedro e Chacon (2016) concluíram que os estudantes com deficiência intelectual têm mais oportunidade de obter sucesso nas diferentes tarefas se forem utilizados softwares educativos nas atividades propostas no contexto sala de aula, tendo ainda verificado que a manipulação dos meios digitais e a assimilação dos conteúdos programáticos depende de formação prévia, em que devem ser utilizadas estratégias de ensino específicas. Nesse contexto, os professores devem atender às competências e dificuldades de cada aluno com deficiência intelectual, a fim de aplicarem estratégias específicas para cada caso (Pedro \& Chacon, 2016, p.12).

Além dos benefícios que as competências digitais trazem no contexto de aprendizagem às pessoas com deficiência ou com necessidades educativas especiais, existem outas vantagens que contribuem também para que se tornem cidadãos ativos, envolvidos e integrados na comunidade. Segundo Parsons (2015), a utilização de meios digitais (nomeadamente de questionários online) em estudos e investigações torna o processo de recolha de dados mais acessível a pessoas com deficiência. A personalização do tamanho dos conteúdos, o acesso a ferramentas de áudio e vídeo e a portabilidade fornecem uma maior facilidade de acesso, apoiando a compreensão e o envolvimento. Neste sentido, as tecnologias digitais podem ser vistas como potenciais instrumentos não só para a acessibilidade e compreensão de ideias e atividades, mas também como instrumentos de tomada de decisão e participação que proporcionam uma visão importante das opiniões e das experiências das pessoas com deficiência (Parsons, 2015). Mesmo em termos de socialização, os meios digitais são uma mais-valia. Jovens com deficiência com idades compreendidas entre os 18 e os 29, que têm uma maior facilidade de acesso à internet do que pessoas mais velhas, estão mais propensos a socializar, comparativamente a pessoas com idades superiores a 30 anos que não utilizam os meios digitais (Council on Disability, 2011).

No que diz respeito às taxas de empregabilidade, as pessoas com deficiência tendem a ter pouca visibilidade no mercado de trabalho e a ser as primeiras a ser dispensadas quando existem cortes no número de funcionários e as últimas a serem contratadas, quando existe um crescimento industrial. Para além disso, existem poucas oportunidades em trabalho em tempo integral (Council on Disability, 2011). No entanto, as tecnologias digitais podem ser um contributo importante para alterar este panorama, uma vez que, atualmente, toda a economia tem como base os meios digitais. Caso as pessoas com deficiência intelectual tenham formação neste âmbito das tecnologias digitais, poderão ser mais facilmente incluídas no mercado trabalho.

\section{Desenvolvimento de Campanhas Audiovisuais de sensibilização}

O desenvolvimento de uma campanha audiovisual começa com uma planificação do conteúdo. É na préprodução que vai ser determinada muito da aparência e qualidade do projeto, pelo que esta fase pesa muito no sucesso das fases seguintes: a produção e a pós-produção (Schenk \& Long, 2012). Qualquer que seja o 
tipo de conteúdo audiovisual, é necessário entender bem os conceitos básicos para a construção de uma boa narrativa e para a escrita de um bom guião, que passam primeiramente por se conseguir definir a história e estabelecer os detalhes sobre os quais rondará o vídeo. Outra vertente associada ao sucesso do conteúdo audiovisual está relacionada com a audiência, sendo bastante importante conhecer para quem se produz a campanha (Schenk \& Long, 2012). Um vídeo de sensibilização, ainda que não sendo um filme, necessita de se centrar numa narrativa, ter uma estrutura e contar uma história visualmente, pelo que o guião também necessita de ter a mesma unidade narrativa de início, meio e fim. Assim, a indicação dada por Schenk e Long (2012) vai no sentido de tentar estabelecer uma ideia concreta do "problema" que se quer retratar no vídeo. Apresentar e explicar o problema constituirá o seu primeiro ato, seguindo-se uma explicação do porquê da necessidade da resolução do problema, para apresentar em seguida uma solução (Schenk \& Long, 2012).

O fenómeno da viralidade e o envolvimento do consumidor em vídeo é uma forma eficaz de divulgar os conteúdos da campanha, e a Internet tem um grande poder no que concerne ao alcance que proporciona. Os vídeos criados para uma campanha podem ser desenvolvidos numa perspetiva interativa que, ao conseguir envolver os consumidores, ainda é responsável por criar relações, sempre na ótica de promoção do conteúdo. Adicionar links de partilha que remetam para redes sociais como o Facebook ou Twitteré uma mais-valia, uma vez que, ao serem dadas as ferramentas que facilitam a sua partilha, os vídeos são mais disseminados nas redes sociais, o que permitirá maior ganho de visibilidade e, consequentemente, maior probabilidade de ser mais visto e por outros públicos (Jenkins \& Feldman, 2011).

No que se relaciona com campanhas de sensibilização dedicadas à deficiência, importa realçar que mudar a forma como as pessoas veem e lidam com a deficiência é um processo lento porque implica transformar o modo como a sociedade está organizada. Uma campanha de sensibilização deve incluir um conhecimento sobre a vida das pessoas com deficiência, de modo a conseguir transmitir uma publicidade positiva. Depois de escolhido o problema e o período de tempo em que se desenvolverá a campanha, é necessário identificar o seu público-alvo de modo a pensar sobre as estratégias indicadas para cada grupo (Fletcher, n.d.).

\section{O processo de Design Participativo e o envolvimento de pessoas com deficiência}

Inicialmente conhecido por design cooperativo, o design participativo tem sido reconhecido, mais recentemente, como co-design. Este processo pode ser visto como um meio de projetar a tecnologia digital envolvendo ativamente os potenciais utilizadores finais como participantes no desenvolvimento do projeto (Benton \& Johnson, 2015).

O sucesso do design participativo está na capacidade de adaptar os seus métodos e diretrizes a contextos novos e em mudança (Dittrich, Eriksén \& Wessels, 2014) e de envolver múltiplos stakeholders, eliminando as relações de poder e permitindo, assim, que os participantes sejam verdadeiros co-designers (Holone \& Herstad, 2013).

Através da inclusão de mais atores, o objeto adquire novas perspetivas e dimensões relevantes importando, no entanto, identificar quem são as pessoas que devem ser incluídas neste processo. Este círculo de envolvidos é passível de ser alterado no decorrer do projeto, muito embora pese a satisfação através dos contributos dados e a relevância que os novos constituintes possam trazer ao projeto (Dittrich et al., 2014). 
Envolver pessoas com deficiência no processo de design participativo constitui um desafio grande, principalmente no caso de deficiências que afetam as funções cognitivas ou de comunicação. Muitas técnicas de design participativo incluem processos de formulação de pensamento e comunicação, que as pessoas com deficiência intelectual têm dificuldade em processar, pelo que as técnicas tradicionais precisam de ser ajustadas a esta realidade (Slegers, Duysburgh, van Rijn \& Hndriks, 2012). Quando se envolve pessoas com deficiência, o processo de design participativo está sujeito a três tipos de tensão. A primeira está relacionada com o tempo do processo, que aumenta significativamente pelo facto de os indivíduos necessitarem de mais tempo para se familiarizarem, estabelecerem uma base de confiança e serem capazes de comunicar. 0 segundo está relacionado com o facto de as pessoas com deficiência não estarem, muitas vezes, habituadas ao papel de tomada de decisão e demorarem a tornar-se participantes ativos no processo. 0 último referese à necessidade de haver um intermediário para estabelecer a comunicação entre o designer e o participante com deficiência, que pode corromper a fidelidade dos dados e ainda ser uma potencial influência para o que é apresentado e omitido (Holone \& Herstad, 2013).

\section{Fases do estudo}

O estudo foi desenvolvido em colaboração com uma Associação que tem um centro de atividades ocupacionais para adultos com deficiência intelectual, para mais facilmente identificar pessoas disponíveis para participar na campanha bem como contar com o apoio de profissionais que acompanham esses utentes. Numa primeira fase foi realizada uma entrevista estruturada aos profissionais de saúde e aos membros da direção da Associação, para se conhecer o tipo de deficiências que os utentes possuíam, bem como as suas características, rotinas e atividades desenvolvidas na Associação. Foi também disponibilizado um questionário a um representante da Associação com o objetivo de ter acesso a informação sobre a existência de tecnologias digitais e audiovisuais na Associação e conhecer o seu uso pelos utentes, bem como averiguar a disponibilidade dos vários funcionários para participar no projeto. Numa fase seguinte, estava também prevista a aplicação de um inquérito por questionário aos utentes participantes, de modo a perceber a utilização que fazem dos meios audiovisuais e digitais, qual o fim e com que frequência os usavam, com vista a melhor caracterizar o grupo e delinear o seu perfil de experiência digital e audiovisual. No entanto, em reunião com as profissionais de saúde do Centro, chegou-se à conclusão que seria melhor aplicar um inquérito por entrevista, predominantemente de respostas fechadas, justificado pelas limitações ao nível da leitura e da escrita dos utentes.

A fase de desenvolvimento da campanha pressupôs a passagem por três fases: pré-produção, produção e pós-produção. A pré-produção envolveu o planeamento da campanha, com a definição do tipo de narrativa e construção do guião e storyboard e com a participação de utentes e funcionários do Centro. A parte da produção, que compreendeu as gravações, também teve a colaboração dos adultos com deficiência e dos terapeutas, quer na realização quer como parte integrante do elenco, e o mesmo aconteceu na fase de pósprodução relativa à edição das imagens, com montagem, edição de cor e sonorização. Ao longo das sessões foram também registadas observações a fim de averiguar a recetividade à experiência das pessoas envolvidas e foi realizada uma pequena discussão para ver os pontos positivos e pontos a melhorar na estratégia utilizada. 
Neste processo marcadamente qualitativo e de cariz etnográfico, a investigadora tornou-se participante, observando e integrando-se no ambiente, ainda que mantendo a distância necessária para o poder descrever sem influenciar (Hoey, 2014).

Numa fase final foi feita a avaliação do produto audiovisual, através da aplicação de um inquérito por questionário online a uma amostra de conveniência. Nesta fase tentou-se aferir o potencial de sensibilização da campanha e compreender se esta poderia efetivamente contribuir para alertar para a problemática da reduzida utilização dos meios digitais pelos adultos com deficiência.

Nas secções seguintes são detalhados os resultados obtidos em cada uma das fases mencionadas.

\section{Caraterização do grupo de participantes e do Centro}

Os elementos participantes foram selecionados pelos profissionais de saúde do Centro, com base no nível de gravidade da sua deficiência. Foram selecionados nove utentes com idades compreendidas entre os 19 e os 39 anos, cinco do género masculino e três feminino, todos com deficiência intelectual moderada, como se pode observar na tabela 1.

Tabela 1 - Perfil dos participantes

\begin{tabular}{|c|c|c|c|c|c|c|}
\hline $\begin{array}{l}\text { Participant } \\
\text { es }\end{array}$ & Género & $\begin{array}{ll}\text { Nível de } & \text { de } \\
\text { gravidade } & \end{array}$ & $\begin{array}{ll}\text { Nível } & \text { de } \\
\text { autonomia } & \end{array}$ & $\begin{array}{l}\text { Escolaridad } \\
\text { e }\end{array}$ & $\begin{array}{lr}\text { Nível } & \text { de } \\
\text { escrita } & \text { e } \\
\text { leitura } & \end{array}$ & $\begin{array}{l}\text { Tipo de atividades } \\
\text { que realizam }\end{array}$ \\
\hline $\begin{array}{l}\text { P1 } \\
(1979)\end{array}$ & $\begin{array}{l}\text { Masculin } \\
\text { o }\end{array}$ & $\begin{array}{l}\text { Deficiência } \\
\text { Moderada e } \\
\text { Deficiência } \\
\text { Física }\end{array}$ & Autónomo & $6^{\circ}$ ano & $\begin{array}{l}\text { Sabe ler e } \\
\text { escrever }\end{array}$ & $\begin{array}{l}\text { Lavagem de } \\
\text { automóveis; } \\
\text { carpintaria; } \\
\text { acompanhamento na } \\
\text { carrinha de } \\
\text { transporte de utentes } \\
\text { do centro }\end{array}$ \\
\hline $\begin{array}{l}\text { P2 } \\
(1993)\end{array}$ & Feminino & $\begin{array}{l}\text { Deficiência } \\
\text { Moderada }\end{array}$ & $\begin{array}{lr}\text { Autónomo, mas } \\
\text { necessita } & \text { de } \\
\text { supervisão } & \end{array}$ & $9^{\circ}$ ano & $\begin{array}{l}\text { Dificuldades } \\
\text { graves em } \\
\text { escrever; } \\
\text { mais } \\
\text { facilidade a } \\
\text { ler, mas } \\
\text { necessita de } \\
\text { apoio }\end{array}$ & $\begin{array}{l}\text { Limpeza e arrumação } \\
\text { de espaços; } \\
\text { lavandaria; } \\
\text { acompanhamento na } \\
\text { carrinha de } \\
\text { transporte de utentes } \\
\text { do centro }\end{array}$ \\
\hline $\begin{array}{l}\text { P3 } \\
\text { (1997) }\end{array}$ & $\begin{array}{l}\text { Masculin } \\
\text { o }\end{array}$ & $\begin{array}{l}\text { Deficiência } \\
\text { Moderada }\end{array}$ & $\begin{array}{l}\text { Necessita de } \\
\text { bastante } \\
\text { supervisão } \\
\text { orientação. } \\
\text { Autónomo na sua } \\
\text { higiene diária }\end{array}$ & $11^{\circ}$ ano & $\begin{array}{l}\text { Sabe ler e } \\
\text { escrever }\end{array}$ & $\begin{array}{l}\text { Oficina de Olaria e } \\
\text { carpintaria (no } \\
\text { centro); atividades } \\
\text { de estimulação e } \\
\text { sócio-recreativas; } \\
\text { acompanhamento na }\end{array}$ \\
\hline
\end{tabular}




\begin{tabular}{|c|c|c|c|c|c|c|}
\hline & & & & & & $\begin{array}{l}\text { carrinha de } \\
\text { transporte de utentes } \\
\text { do centro; centro de } \\
\text { informática } \\
\text { terapêutica }\end{array}$ \\
\hline $\begin{array}{l}\text { P4 } \\
(1971)\end{array}$ & $\begin{array}{l}\text { Masculin } \\
0\end{array}$ & $\begin{array}{l}\text { Deficiência } \\
\text { Ligeira } \\
\text { Deficiência } \\
\text { Auditiva }\end{array}$ & $\begin{array}{lr}\text { Autónoma } & \text { mas } \\
\text { necessita } & \text { de } \\
\text { supervisão } & \end{array}$ & Sem info & $\begin{array}{l}\text { Conhece as } \\
\text { letras e } \\
\text { escreve } \\
\text { pequenas } \\
\text { palavras }\end{array}$ & Apoio na cozinha \\
\hline $\begin{array}{l}\text { P5 } \\
\text { (1993) }\end{array}$ & Feminino & $\begin{array}{l}\text { Deficiência } \\
\text { Moderada }\end{array}$ & $\begin{array}{lr}\text { Autónoma } & \text { mas } \\
\text { necessita } & \text { de } \\
\text { supervisão } & \end{array}$ & $9^{\circ}$ ano & $\begin{array}{l}\text { Sabe ler e } \\
\text { escrever }\end{array}$ & $\begin{array}{l}\text { Lavagem de } \\
\text { automóveis; } \\
\text { carpintaria; } \\
\text { acompanhamento na } \\
\text { carrinha de } \\
\text { transporte de utentes } \\
\text { do centro }\end{array}$ \\
\hline $\begin{array}{l}\text { P6 } \\
\text { (1994) }\end{array}$ & Feminino & $\begin{array}{l}\text { Deficiência } \\
\text { Moderada }\end{array}$ & $\begin{array}{lr}\text { Autónoma } & \text { mas } \\
\text { necessita } & \text { de } \\
\text { supervisão } & \end{array}$ & $9^{\circ}$ ano & $\begin{array}{l}\text { Escreve } \\
\text { algumas } \\
\text { palavras pelo } \\
\text { método de } \\
\text { ditar as letras, } \\
\text { e consegue } \\
\text { ler algumas } \\
\text { palavras }\end{array}$ & $\begin{array}{l}\text { Limpeza e arrumação } \\
\text { de espaços; } \\
\text { lavandaria; } \\
\text { acompanhamento na } \\
\text { carrinha de } \\
\text { transporte de utentes } \\
\text { do centro }\end{array}$ \\
\hline $\begin{array}{l}\text { P7 } \\
(1977)\end{array}$ & $\begin{array}{l}\text { Masculin } \\
0\end{array}$ & $\begin{array}{l}\text { Deficiência } \\
\text { Moderada }\end{array}$ & $\begin{array}{ll}\text { Necessita } & \text { de } \\
\text { bastante } & \\
\text { supervisão } & \text { e } \\
\text { orientação; } & \\
\text { autónomo } & \text { na } \\
\text { higiene diária } & \end{array}$ & Sem info & $\begin{array}{l}\text { Dificuldades } \\
\text { graves em ler } \\
\text { e escrever } \\
\text { (conhece as } \\
\text { letras e } \\
\text { consegue ler } \\
\text { algumas } \\
\text { palavras) }\end{array}$ & $\begin{array}{l}\text { Massagens; tirar } \\
\text { cafés no bar; oficinas } \\
\text { de olaria e carpintaria } \\
\text { (do centro); } \\
\text { atividades de } \\
\text { estimulação e sócio- } \\
\text { recreativas }\end{array}$ \\
\hline $\begin{array}{l}\text { P8 } \\
(1985)\end{array}$ & $\begin{array}{l}\text { Masculin } \\
\text { o }\end{array}$ & $\begin{array}{l}\text { Deficiência } \\
\text { Moderada }\end{array}$ & $\begin{array}{ll}\text { Necessita } & \text { de } \\
\text { bastante } & \\
\text { supervisão } & \text { e } \\
\text { orientação.; } & \\
\text { autónomo } & \text { na } \\
\text { higiene diária } & \end{array}$ & Sem info & $\begin{array}{l}\text { Não sabe ler } \\
\text { nem escrever } \\
\text { (só sabe o } \\
\text { nome própria) }\end{array}$ & $\begin{array}{l}\text { - Informática } \\
\text { terapêutica; oficinas } \\
\text { de olaria e carpintaria } \\
\text { (do centro; } \\
\text { atividades de } \\
\text { estimulação e sócio- } \\
\text { recreativas }\end{array}$ \\
\hline
\end{tabular}


Relativamente ao questionário sobre os recursos digitais e audiovisuais do Centro que foi disponibilizado, os dados obtidos revelaram que o Centro está equipado com um computador fixo e dois computadores portáteis para utilização pelos utentes e que possui acesso à internet por Wi-Fi, permitindo aos utentes aceder à internet não só através dos computadores, como a partir dos seus telemóveis pessoais. Em relação aos meios audiovisuais, o Centro possui duas televisões localizadas na sala de estar e no bar, que os utentes utilizam ao final do dia, sempre que solicitam, ou durante a atividade de visualização de filmes, escolhidos pelos utentes, que o Centro promove. A sala de estar, o bar e a sala Snoezelen estão equipados com três leitores de DVD usados para ver filmes e passar música.

Os resultados dos inquéritos por entrevista aos utentes que participaram no estudo revelaram que quatro dos nove participantes consomem diariamente conteúdos audiovisuais (como filmes, programas de televisão, videoclipes), havendo apenas um entrevistado que não vê qualquer tipo de conteúdo. Os outros quatro participantes responderam que veem este tipo de conteúdos cerca de 3 vezes por semana.

Em relação ao tipo de conteúdos visionados, a maioria dos participantes referiu optar por vídeos informativos, humorísticos e filmes (6/9), mas os videoclipes também são bastante consumidos (5/9), sendo que só um número reduzido (2/9) assiste a outros tipos. Nenhum dos entrevistados tem por hábito ver reality shows, talk shows ou vídeos institucionais. O computador e a televisão são os meios mais utilizados (7/9), enquanto o telemóvel é utilizado apenas por três dos nove participantes. Nenhum deles indicou ir ao cinema com frequência nem utilizar outro tipo de dispositivos, como tablet, para ver vídeos.

Sete dos nove participantes indicaram possuir telemóvel com câmara fotográfica, sendo que cinco deles costumam tirar fotografias com o telemóvel ou filmar, em média, três vezes por semana. Um dos elementos utiliza esta funcionalidade raramente, enquanto outro utiliza todos os dias. As fotografias e/ou vídeos são essencialmente de familiares, amigos, dos próprios, ou dos animais de estimação.

A questão relativa ao acesso à internet teve respostas muito dispersas. Um participante admitiu nunca aceder à internet, um outro membro do grupo fá-lo raramente e outro cerca de três vezes por semana. Os outros entrevistados utilizam a internet diariamente (4/9) ou cerca de cinco vezes por semana (2/9). O meio utilizado por todos para aceder à internet é o computador, sendo que cinco dos participantes diz utilizar, também, o telemóvel para este fim.

$\mathrm{Na}$ internet, para além da utilização das redes sociais (5/8), sete dos oito participantes assistem a vídeos e ouvem música, alguns utilizam a internet para navegar por websites do seu interesse e fazer chamadas de vídeo (3/8) e um número reduzido utiliza o e-mail (2/8). Atividades como pesquisar serviços, efetuar compras ou jogar online não são realizadas por nenhum dos membros do grupo. Seis dos oito inquiridos indicaram possuir conta numa rede social, utilizando apenas o Facebook.

Pode, portanto, concluir-se que todos os participantes do grupo de trabalho têm acesso a meios digitais e audiovisuais, embora nem todos os utilizem diariamente. $\mathrm{O}$ seu uso cinge-se maioritariamente a tarefas mais simples, direcionadas para a comunicação interpessoal. A maioria está inscrito no Facebook, estando, portanto, em contacto através das redes sociais. 


\section{Desenvolvimento da Campanha audiovisual de sensibilização}

A pré-produção é a primeira parte do processo de produção de vídeo e é responsável, em grande parte, pela qualidade do projeto porque engloba vários aspetos importantes, que vão do planeamento, calendarização, construção do storyboard, até a detalhes como a escolha da câmara e definição do cenário (Schenk \& Long, 2012).

A primeira sessão de trabalho, dedicada ao início desta fase, iniciou com uma breve explicação do objetivo do projeto seguida de uma parte na qual os participantes tiveram contacto com diferentes campanhas e tiveram a oportunidade de opinar sobre as mesmas. Foram mostrados três tipos de campanhas audiovisuais (Nike: Unlimited Will, Entre Rodas e Batom e Associação Salvador - 5 minutos fazem a diferença) ${ }^{1}$, com caraterísticas diferentes de duração, composição cromática e sonorização e foi desenvolvida uma atividade com o grupo por forma a conseguir perceber o que consideravam mais interessante para a campanha a desenvolver neste projeto.

A fim de recolher dados sobre as preferências dos participantes relativamente às campanhas visionadas e a compreender o que estes gostariam que fosse retratado na campanha do projeto em curso, os participantes foram convidados a votar, através de símbolos impressos num cartão, no vídeo que gostaram mais e menos, segundo várias dimensões: duração, música, tom (positivo ou negativo) do vídeo e interação entre personagens. Uma vez que os participantes estavam familiarizados com a rede social Facebook e o projeto se desenvolve em torno dos meios digitais, optou-se recorrer aos símbolos like e de reação zangado, muito conhecidos desta rede social (ver figura 1). Esta opção pode ser vista como uma estratégia para envolver mais os participantes no ponto de vista prático, uma vez que se torna uma forma mais engraçada de participar e dar opinião, criando também maior proximidade e abrindo caminho para a discussão.

Figura 1: Símbolos do Facebook, utilizados na votação
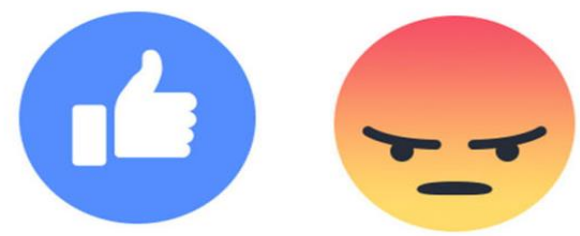

Numa fase seguinte, foi feita uma análise do conteúdo de cada vídeo em conjunto com os participantes, de modo a averiguar se os participantes tinham compreendido a mensagem inerente a cada um. No geral, a maior parte dos elementos compreendeu o objetivo no primeiro contacto com o vídeo, ou depois de ouvir a discussão gerada entre as visualizações.

Os participantes mantiveram-se atentos durante a passagem das campanhas de sensibilização tendo havido, no entanto, uma redução do número de participantes para oito quando um dos elementos se ausentou a

https://www.youtube.com/watch?v=OiUYOXDVSRw

https://www.youtube.com/watch?v=n-HkPtwERmU https://www.youtube.com/watch?v=8xrME8GIW2Y 
meio da sessão. O facto de essa participante ter surdez trouxe-lhe dificuldades em conseguir acompanhar o que estava a ser discutido, o que a levou a abandonar a sala.

Relativamente às opiniões acerca das características do vídeo, a maioria dos participantes votou no vídeo mais curto Nike: Unlimited Will (4 votos a favor e 2 contra) e no vídeo em que se conta uma história que vai revelando as limitações ao longo do vídeo e não desde o início (5 votos a favor do vídeo Entre Rodas $e$ Batom). No que diz respeito ao estilo, todos votaram no vídeo Nike: Unlimited Will, um vídeo positivo, com uma música animada, em que as personagens interagem e que não é constituído apenas por música de fundo.

Uma vez delineado que se pretendia um vídeo curto com cerca de um minuto, a partir das votações e discussão em torno dos vídeos, o processo de construção do guião revelou-se relativamente simples.

O guião deve seguir um formato de página padrão, o screenplay, a fim de facilitar o processo de produção, ter noção do comprimento e do ritmo das ações (Schenk \& Long, 2012), pelo que se fez uso do programa Celtx na sua construção. Ascher e Pincus (2013) defendem que a durante a escrita de um guião se deve considerar atentamente que detalhes são importantes, mas também quais se podem dispensar, e falam acerca da conjetura geral de que os guiões no formato padrão são executados numa página por minuto (Ascher \& Pincus, 2013). Tendo em conta esta previsão, o guião construído incluiu quatro cenas breves, que ocupavam cerca de uma página.

Por se ter optado por um vídeo com um tom positivo, a narrativa desenvolvida segue esses traços incluindo, simultaneamente, o recurso a equipamentos eletrónicos, redes sociais e a ferramentas de acessibilidade.

A ideia para a narrativa surgiu durante um processo de brainstorming com as profissionais de saúde do Centro. Por se tratar de um processo difícil de executar com os participantes, por terem dificuldades em expressar-se, em dar ideias e discutir, optou-se por realizar esta tarefa apenas com estas terapeutas que acompanhavam de perto a realidade dos participantes. Assim, surgiu a ideia de mostrar o uso que as pessoas com deficiência intelectual podem fazer dos meios digitais, mostrando que as dificuldades que enfrentam no seu quotidiano podem ser ultrapassadas, ainda que para isso haja a necessidade de utilizar ferramentas específicas - as ferramentas de acessibilidade. O vídeo tem um duplo objetivo uma vez que, para além de alertar para a contínua necessidade de desenvolver meios mais acessíveis para as pessoas com deficiência intelectual, mostra que os meios digitais aproximam as pessoas com deficiência das pessoas sem deficiência e que melhoram e ajudam nos processos de socialização. No caso das pessoas com deficiência intelectual, as tecnologias digitais e a internet, que por vezes são vistas como algo que quebra a proximidade física entre as pessoas, podem mesmo aproximar, por facilitar a comunicação. No vídeo pretende-se mostrar esse lado, daí ter-se pensado em criar este mundo em que o personagem principal faz uso dos meios digitais, não só para a pesquisa acerca de um evento como para convidar os amigos para a atividade e, no final, há a passagem do virtual para o encontro físico.

Numa fase seguinte foi desenvolvido o storyboard, uma ferramenta crucial que prepara para as gravações, uma vez que obriga a tomar várias decisões que não surgiram aquando a construção do guião (Schenk \& Long, 2012), por ser uma sequência de desenhos representativa das várias ações a serem gravadas (Ascher \& Pincus, 2013).

$\mathrm{Na}$ fase de produção existem muitas variáveis a ter em consideração (como atores, equipa de trabalho, localizações, adereços, guarda-roupa, condições meteorológicas, entre outras), que necessitam de ser ponderadas antes de se iniciarem as gravações (Schenk \& Long, 2012). Assim sendo, tratou-se de preencher 
as folhas de serviço, que atuam como calendários de produção, que integram não só as pessoas e os recursos necessários para cada cena como a ordem pela qual se vão gravar as cenas e que funcionam como potenciadores da eficiência enquanto permitem a flexibilidade no caso de ocorrer qualquer eventualidade (Ascher \& Pincus, 2013).

Os locais de gravação foram decididos pela investigadora e pela terapeuta. Por questões logísticas, as gravações tiveram lugar nos vários espaços do Centro e nos arredores.

Depois da validação dos documentos de pré-produção pela psicóloga do Centro seguiu-se a fase de produção, que foi constituída por uma sessão de trabalho dedicada às gravações. A sessão teve início com uma explicação a cada participante sobre técnicas de gravação de imagem e áudio e sobre o modo de funcionamento do material, recorrendo-se a post-its coloridos que foram colados ao material e numerados tendo em consideração a ordem pela qual seriam utilizados. As gravações seguiram a ordem das cenas estipuladas no guião e com recurso ao storyboard.

Os participantes foram envolvidos em completo na produção do vídeo. Para cada cena, uns foram destacados para participar enquanto atores, enquanto os outros ficaram responsáveis pela captação do vídeo e do áudio, tendo assim passado pelos vários papéis relativos à produção (figura 2).

Figura 2: Produção do vídeo de sensibilização
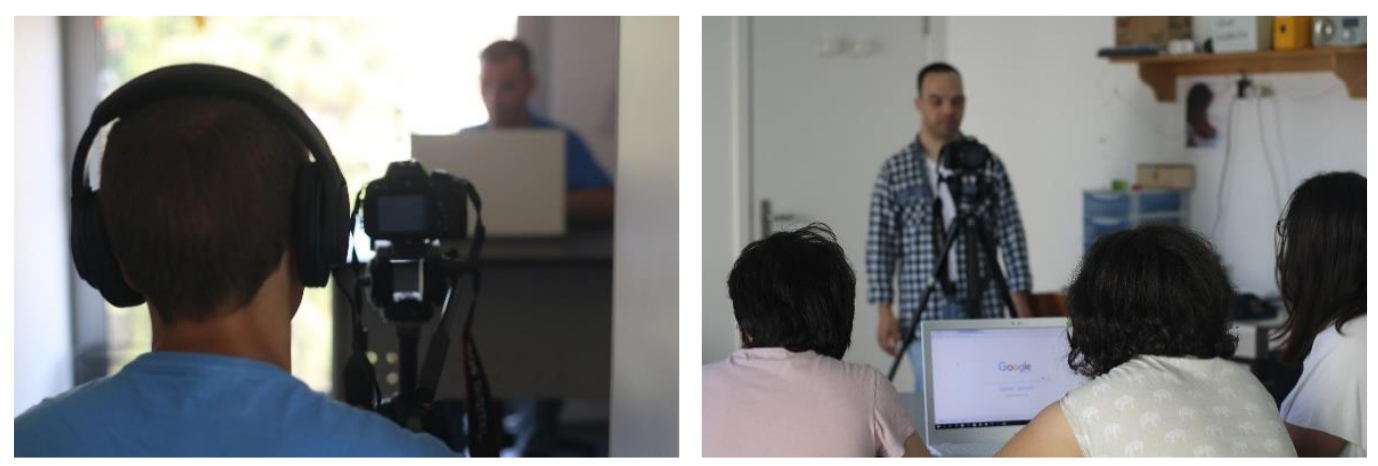

As gravações foram bem-sucedidas, ainda que tenham sido feitas algumas alterações ao guião na parte final do vídeo. Devido a condicionamentos de tempo e deslocação, teve-se que alterar o local de uma das cenas. Durante o processo, os diálogos informais com os participantes permitiram perceber que o dia de produção agradou à maioria, que nunca tinha tido semelhante experiência.

Seguiu-se a fase da pós-produção que englobou a montagem e sonorização, com a colocação dos voiceover e efeitos sonoros. Foram selecionadas três músicas de Attribution-ShareAlike (CC BY-SA 4.0) segundo as licenças de Creative Commons, que permitem partilhar, copiar, distribuir e adaptar as obras, com a devida referência ao autor. As três músicas são distintas, sendo que a primeira - Sunny Street de David Szesztay ${ }^{2}$ - é um instrumental de piano, que denota uma certa esperança; a segunda - Happy Song Instrumenta/ de Pachyderm ${ }^{3}$ - é uma música alegre com notas de baixo, guitarra, percussão e sintetizador; e a última -

\footnotetext{
${ }^{2}$ http://freemusicarchive.org/music/David_Szesztay/20170730112627550/Sunny_Street

${ }^{3} \mathrm{http}: / /$ freemusicarchive.org/music/Pachyderm/Live_at_the_Fillmore_instrumental_version/Pachyderm_-

_Live_at_the_Fillmore_Ultra-Deluxe_Instrumental_Version_-_14_Happy_Song_instrumental
} 
Corporate (Innovative) de Scott Holmes ${ }^{4}$ - tem um cariz mais motivacional, bastante alegre e é mais longa que as outras opções.

Outro fator que se teve em consideração na pós-produção foi a composição cromática do vídeo. Assim sendo, foram criadas três versões, com diferentes correções de cor. A figura seguinte (figura 3) apresenta uma sequência de frames que mostram a diferença de cor entre as gravações originais (topo, lado esquerdo) e as três versões de edição, onde se trabalhou com as curvas RGB.

Figura 3: Comparação relativa à correção de cor da frame

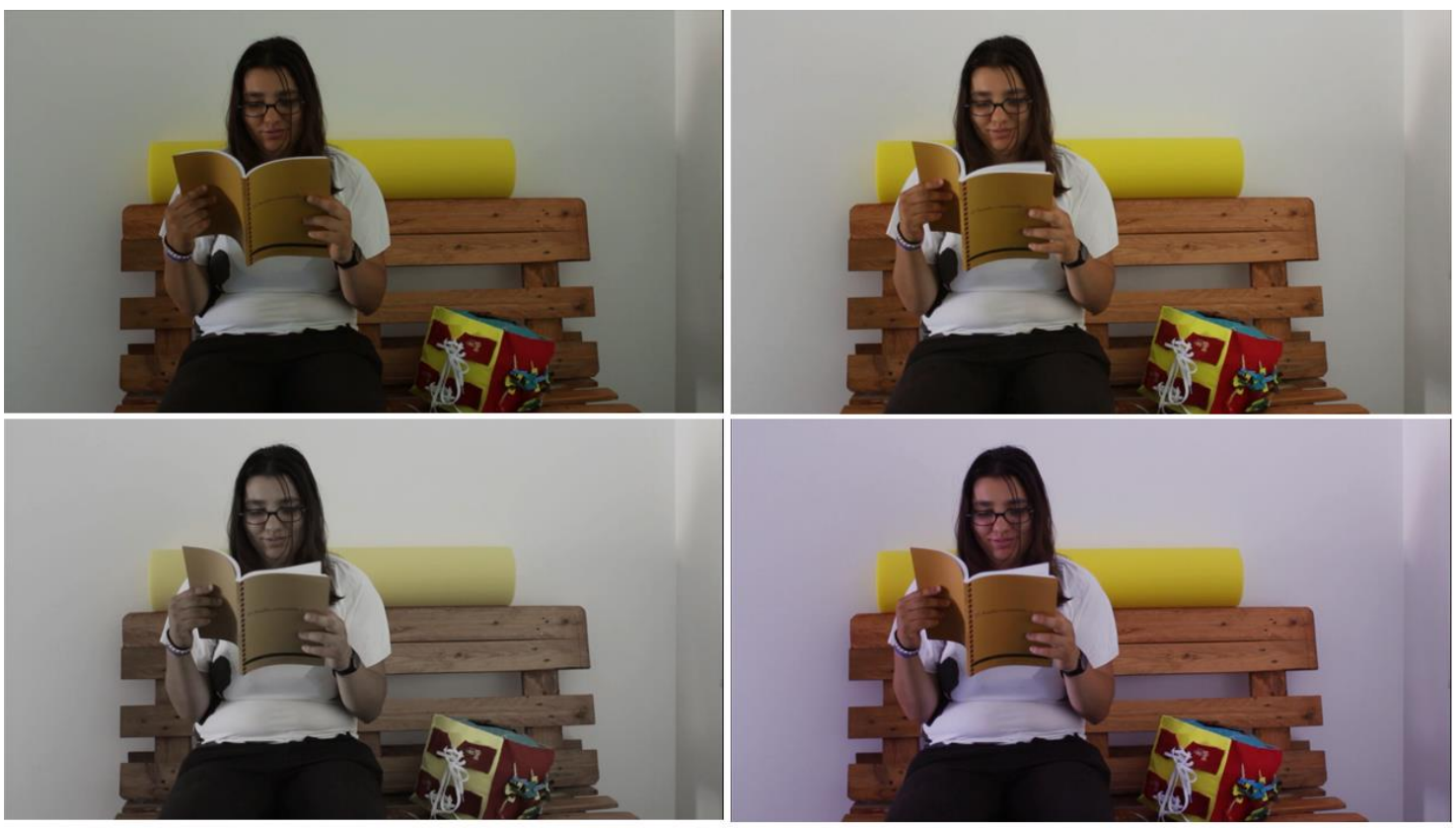

Na primeira versão (topo, lado direito) foram utilizados tons mais quentes e em simultâneo mais brilhantes, que the conferem mais vivacidade quando comparado com as imagens originais. Na versão dois apostou-se num registo diferente, com menos contraste e saturação, o que originou uma imagem com menos vida, com aproximação de tons cinza. Na última versão foi aumentado o nível de azul, o que tornou a imagem mais arroxeada, ainda que se tenha mantido uma imagem com cores vivas.

Foi realizada uma votação utilizando novamente os símbolos do Facebook, tendo-se verificado que todos os participantes votaram na segunda música apresentada - Happy Song Instrumental de Pachyderm - e na primeira versão de composição cromática do vídeo.

Para finalizar, foram colocadas algumas mensagens para reforçar a sensibilização e contextualizar o tema do vídeo. No início, utilizam-se dados estatísticos acerca do número de pessoas com deficiência intelectual e é apresentada a informação de que a maioria dessas pessoas não faz uso de meios digitais. No fim do vídeo, aparece a frase "se a comunicação não tiver limites... a vontade/diversão/alegria/amizade não tem limites". Esta mensagem pretende tocar na questão das barreiras que as pessoas com deficiência intelectual enfrentam quando utilizam alguns tipos de meios digitais, mas também sublinhar que se as tecnologias http://freemusicarchive.org/music/Scott_Holmes/Corporate_Motivational_Music/Scott_Holmes_-_04__Corporate_Innovative 
estiverem preparadas com ferramentas de acessibilidade é possível fazer uso delas e beneficiar em termos de socialização e autonomia.

Devido a algumas opções que tiveram que ser tomadas na fase de produção, ocorreram alguns problemas que tiveram de ser resolvidos em pós-produção. Um exemplo foi a necessidade de utilizar focagem automática face às dificuldades dos participantes, o que originou algumas imagens desfocadas. A solução encontrada foi utilizar imagens criadas digitalmente e capturas de ecrã. Em termos de pós-produção, foram tidos em consideração alguns aspetos no que diz respeito às transições entre algumas frames, com a utilização do efeito "desvanecer" entre cenas ou o efeito de "desfoque" para fazer uma transição mais suave.

\section{Avaliação do potencial de sensibilização da Campanha}

Finda a pós-produção aplicou-se um inquérito por questionário de avaliação do potencial de sensibilização do vídeo desenvolvido ${ }^{5}$ para a importância do uso dos meios digitais por parte dos adultos com deficiência intelectual. O questionário foi criado através da plataforma Google Forms e aplicado a uma amostra por conveniência, tendo a investigadora partilhado o vídeo no Facebook através de mensagem privada, publicado em grupos e no perfil pessoal. Os inquiridos foram convidados a assistir ao vídeo apresentado no início do questionário e, em seguida, a responder a um conjunto de perguntas que pretendiam aferir de que forma o vídeo tinha contribuído para promover a sensibilização para a importância do uso dos meios digitais pelos adultos com deficiência.

Obtiveram-se 93 respostas, em que a maioria dos inquiridos tinha entre 18 e 24 anos (63,4\%), idades próximas às dos adultos com deficiência que participaram no projeto, sendo também a maior parte dos inquiridos do sexo feminino $(64,5 \%)$.

$62,4 \%$ dos participantes revelaram conhecer pessoas com deficiência intelectual e 61,3\% indicaram não ter conhecimentos das ferramentas de acessibilidade apresentadas no vídeo. Em relação à importância da temática do uso dos meios digitais pelos adultos com deficiência, numa escala de 1 a 5 , de nada relevante para muito relevante, $54,8 \%$ dos participantes consideraram que é um tema muito relevante, $38,7 \%$ consideraram relevante e apenas $6,5 \%$ avaliaram como sendo um tema de médio interesse.

A nível de edição de vídeo, foram colocadas questões acerca da montagem, ritmo, duração e do som. A maioria dos inquiridos (55,9\%) considerou que a montagem e o ritmo eram adequados, $22,6 \%$ avaliaram como bastante adequados, $19,4 \%$ aferiram ter um nível razoável de adequabilidade e 2,2\% pouco adequado. Em termos de música utilizada, 35,5\% determinaram como bastante adequada, 37,6\% indicaram como sendo adequada, $18,3 \%$ assinalaram que a um nível intermédio de adequabilidade, $6,5 \%$ consideraram a música pouco adequada e 2,2\% avaliaram como nada adequada.

A pergunta acerca da duração do vídeo teve as seguintes respostas: $32,3 \%$ avaliaram como bastante adequado, 46,2\% indicaram tratar-se de uma duração adequada, , 16,1\% como razoável, 4,3\% consideraram como pouco adequada e $1,1 \%$ nada adequada.

A maioria dos inquiridos $(52,7 \%)$ responderam que ponderaria partilhar o vídeo nas suas redes sociais, $36,6 \%$ assinalaram a opção talvez e 10,8\% que não iria partilhar. Para aferir acerca do poder de

\footnotetext{
${ }^{5}$ A versão final do vídeo está disponível em https://www.youtube.com/watch?v=PfHGV6WhMkM.
} 
sensibilização do vídeo, criou-se uma pergunta com resposta de escala 1 a 5, de nada sensibilizador para muito sensibilizador. $23,7 \%$ dos participantes consideraram, o vídeo como muito sensibilizador, 51,6\% sensibilizador, $18,3 \%$ assinalaram médio nível de poder de sensibilização e 6,5\% avaliaram como pouco sensibilizador.

O último espaço do questionário foi dedicado a críticas e sugestões e teve comentários bastante positivos, como "...é uma temática muito interessante por ser pertinente na sociedade atual e ao mesmo tempo ainda pouco desenvolvida. Faltam mais ferramentas para esta população e campanhas como esta são muito importantes para gerar alerta", "excelente iniciativa, a temática é deveras importante!", "muito explícito e explicativo". Um dos participantes do estudo criticou a falta de "maior detalhe e melhores condições de captura de som" e um outro o facto de as pessoas invisuais não serem incluídas no vídeo e não ser totalmente evidente que são pessoas com deficiência cognitiva. O mesmo participante sugere que um próximo vídeo inclua as dificuldades encontradas no dia-a-dia de pessoas com deficiência intelectual no uso das ferramentas digitais de comunicação e as estratégias utilizadas para as ultrapassar.

Pode, assim, considerar-se que o vídeo produzido conseguiu mostrar uma perspetiva de uso dos meios digitais por parte de adultos com deficiência intelectual, fazendo referência a ferramentas de acessibilidade que a maioria dos inquiridos não conhecia.

\section{Considerações finais}

A presente investigação assentou em três objetivos: conhecer os usos das tecnologias pelos adultos com deficiência e como estes podem beneficiar a sua qualidade de vida desenvolvimento uma campanha audiovisual que alertasse para a necessidade da maior utilização de meios digitais pelos adultos com deficiência intelectual e promovesse um maior uso nesse público e; o recurso à abordagem de design participativo para a construção dessa campanha .

Uma vez que a revisão de literatura não deu muitas pistas acerca do uso e possíveis impactos dos media digitais na vida dos adultos com deficiência, este estudo permitiu compreender melhor estes aspetos, ainda que não possam ser tiradas conclusões muito generalizadas por se ter trabalhado com um grupo pequeno considerando o universo de pessoas com deficiência intelectual. Através das entrevistas estruturadas e pela observação durante as sessões de trabalho foi possível caracterizar o perfil destas pessoas, traçando assim uma imagem real do seu quotidiano. Concluiu-se que os participantes fazem uso dos meios digitais, ainda que de forma básica. Utilizam a internet sobretudo para utilizar as redes sociais, ouvir música e ver vídeos, o que os torna mais independentes, autónomos e sociais, contribuindo para um aumento da qualidade dos seus momentos de lazer e potenciando as relações sociais, a criação e a manutenção de amizades.

A revisão bibliográfica realizada contribuiu para aprofundar o conhecimento sobre o recurso à abordagem de design participativo e para apoiar a adequação de métodos e técnicas a utilizar para o cumprimento dos objetivos primários dispostos anteriormente. Não obstante, houve aspetos que tiveram de ser considerados e adaptados aquando as sessões de trabalho. Deu-se o caso de algumas pessoas do grupo selecionado não estarem predispostas a participar em certas fases das sessões, ou terem certas dificuldades no sentido de não conseguirem adquirir em tempo útil conhecimentos técnicos no âmbito da edição de vídeo. De forma a ultrapassar estas limitações optou-se por, ao invés de participarem em todas as fases do projeto, os seus 
contributos serem focados em tomadas de decisão através da apresentação de várias opções. Outra forma de combater estas dificuldades foi trabalhar não só com os utentes mas também com os profissionais do Centro.

Findo o processo, pode dizer-se que os resultados obtidos são um contributo para o complemento do estado de arte pois, apesar de terem sido apresentadas algumas publicações de referência no âmbito do desenvolvimento de campanhas audiovisuais, não foram, até ao momento, encontradas referências para o desenvolvimento de uma campanha de sensibilização envolvendo adultos com deficiência. A investigação pode, portanto, ser relevante para dar novas pistas sobre o design participativo, uma vez que o grupo de pessoas com deficiência intelectual do Centro foi participante na construção da campanha audiovisual de sensibilização para o uso dos meios digitais. O mundo da deficiência e do audiovisual poderá ficar mais enriquecido com o artefacto produzido uma vez que seguiu as sugestões apresentadas na revisão bibliográfica.

Quanto às limitações do estudo, o facto de serem pessoas com deficiência intelectual e precisarem de acompanhamento e apoio para se expressarem pode ter condicionado os resultados obtidos, considerando que nem sempre foi possível compreender e integrar a visão dos participantes. Face ao tipo de estudo, considera-se que teria sido complicado trabalhar com um grupo maior, no entanto pode apontar-se o tamanho reduzido da amostra como limitação no sentido em que não permite tirar conclusões generalizadas no que concerne ao estudo dos usos que as pessoas com deficiência intelectual fazem dos meios digitais. Outra limitação deve-se a não se ter estudado o efeito da campanha de sensibilização num contexto não de conveniência (publicando a campanha por um período longo de tempo e junto de um grupo diversificado de pessoas).

Estudos futuros podem envolver pessoas com deficiência intelectual, até com outros níveis de gravidade, noutro tipo de atividades da realização e produção de vídeo e englobar tarefas mais práticas e complexas, que não apenas a tomada de decisão através de votações.

\section{Referências Bibliográficas}

Ala-Mutka, K. (2011). Mapping Digital Competence: Towards a Conceptual Understanding. Joint Research Centre. Retrieved from http://ftp.jrc.es/EURdoc/JRC67075_TN.pdf

Alsalem, M. A. (2016). Redefining Literacy: The Realities of Digital Literacy for Students with Disabilities in K-12. Journal of Education and Practice, 732), 205-215.

American Psychiatric Association. (2013). Diagnostic and Statistical Manual of Mental Disorders (p. 991). Arlington: American Psychiatric Association. https://doi.org/10.1176/appi.books.9780890425596.744053

Ascher, S., \& Pincus, E. (2013). The Filmmakers Handbook - A Comprehensive Guide for the Digital Age. England: Plume.

Benton, L., \& Johnson, H. (2015). Widening participation in technology design: A review of the involvement of children with special educational needs and disabilities. International Journal of Child-Computer Interaction, 3, 23-40. https://doi.org/10.1016/j.ijcci.2015.07.001

Burgstahler, S. (2012). Working Together: People with Disabilities and Computer Technology. University of 
Washington.

Retrieved

from

http://www.washington.edu/doit/sites/default/files/atoms/files/wtcomp.pdf

Burgstahler, S. (2015). Opening Doors or Slamming Them Shut? Online Learning Practices and Students with Disabilities. Social Inclusion, 3(6), 69. https://doi.org/10.17645/si.v3i6.420

Chadwick, D., Wesson, C., \& Fullwood, C. (2013). Internet Access by People with Intellectual Disabilities: Inequalities and Opportunities. Future Internet, 5(3), 376-397. https://doi.org/10.3390/fi5030376

Council on Disability, N. (2011). The Power of Digital Inclusion: Technology's Impact on Employment and Opportunities for People with Disabilities. Retrieved from http://sonify.psych.gatech.edu/ walkerb/classes/assisttech/pdf/NationalCouncilOnDisability(2011 ).$p d f$

Dittrich, Y., Eriksén, S., \& Wessels, B. (2014). Learning through situated innovation why the specific is crucial for participatory design research. Scandinavian Journal of Information Systems, 26(1), 29-56.

Eshet-Alkalai, Y. (2012). Thinking in the Digital Era: A Revised Model for Digital Literacy. Issues in Informing Science and Information Technology, 9, 267-276. https://doi.org/10.28945/1621

Gilmore, L., \& Cuskelly, M. (2014). Vulnerability to Loneliness in People with Intellectual Disability: An Explanatory Model. Journal of Policy and Practice in Intellectual Disabilities, 11(3), 192-199. https://doi.org/10.1111/jppi.12089

Harkin. (2010). Rosa's Law. Retrieved from https://www.congress.gov/111/crpt/srpt244/CRPT111srpt244.pdf

Hoey, B. A. (2014). A Simple Introduction to the Practice of Ethnography and Guide to Ethnographic Fieldnotes. Marshall Digital Scholar, (June), 1-10. Retrieved from http://works.bepress.com/cgi/viewcontent.cgi?article=1022\&context=brian_hoey

Holone, H., \& Herstad, J. (2013). Three tensions in participatory design for inclusion. In SIGCHI Conference on Human Factors in Computing Systems - CHI '13 (p. 2903). Paris. https://doi.org/10.1145/2470654.2481401

Jenkins, B., \& Feldman, L. (2011). Consumer Sharing of Viral Video Advertisements: A Look into Message and Creative Strategy Typologies and Emotional Content.

Office for National Statistics. Internet users in the UK:2016, Office for National Statistics § (2016). Retrieved from

https://www.ons.gov.uk/businessindustryandtrade/itandinternetindustry/bulletins/internetusers/2 016

Parsons, S. (2015). The Potential of Digital Technologies for Transforming Informed Consent Practices with Children and Young People in Social Research. Social Inclusion, 3(6), 56-68. https://doi.org/10.17645/si.v3i6.400

Pedro, K. M., \& Chacon, M. C. M. (2016). TECNOLOGIAS DIGITAIS E INCLUSÃO: UMA EXPERIÊNCIA SOBRE ESTUDANTES COM DEFICIÊNCIA INTELECTUAL. SIED:EnPED - Simpósio Internacional de Educação a DistâNcia e Encontro de Pesquisadores Em Educação a DistâNcia, O(0). Retrieved from http://www.sied-enped2016.ead.ufscar.br/ojs/index.php/2016/article/view/1015/913

Reynolds, T., Zupanick, \& Dombeck, M. (2013). Intellectual Disability and Severity Codes. Retrieved January 9, 2017, from https://www.mentalhelp.net/articles/intellectual-disability-and-severity-codes/

Riina, V., Punie, Y., Carretero, S., \& Van den Brande, L. (2016). DigComp 2.0: The Digital Competence 
Framework for Citizens. https://doi.org/10.2791/11517

Schenk, S., \& Long, B. (2012). The Digital Filmmaking Handbook (4th ed.). Cengage Learning. Retrieved from http://www.thedigitalfilmmakinghandbook.com/

Simplican, S. C., Leader, G., Kosciulek, J., \& Leahy, M. (2015). Defining social inclusion of people with intellectual and developmental disabilities: An ecological model of social networks and community participation. Research in Developmental Disabilities, 38, 18-29. https://doi.org/10.1016/j.ridd.2014.10.008

Slegers, K., Duysburgh, P., van Rijn, H., \& Hendriks, N. (2012). Participatory design for users with impairments affecting cognitive functions and communication skills. Proceedings of the 12th Participatory Design Conference on Exploratory Papers Workshop Descriptions Industry Cases Volume 2 - PDC '12, 141. https://doi.org/10.1145/2348144.2348190

Suria, R. (2017). Redes virtuales y apoyo social percibido en usuarios con discapacidad: análisis según la tipología, grado y etapa en la que se adquiere la discapacidad. Escritos de Psicología / Psychological Writings, 10(1), 31-40. https://doi.org/10.5231/psy.writ.2017.21403

Tanis, E. S., Palmer, S., Wehmeyer, M., Davies, D. K., Stock, S. E., Lobb, K., \& Bishop, B. (2012). Self-report computer-based survey of technology use by people with intellectual and developmental disabilities. Intellectual and Developmental Disabilities, 5011), 53-68. https://doi.org/10.1352/1934-955650.1 .53

Wilson, N. J., Jaques, H., Johnson, A., \& Brotherton, M. L. (2016). From Social Exclusion to Supported Inclusion: Adults with Intellectual Disability Discuss Their Lived Experiences of a Structured Social Group. Journal of Applied Research in Intellectual Disabilities: JARID. https://doi.org/10.1111/jar.12275 